\title{
Design of operational application system of cruise missile supported by meteorological and marine information
}

\author{
Jian Hou ${ }^{1,}$, Xiaqiong $\mathrm{Yu}^{2}$, Jiajia Wang ${ }^{1}$, and Deng Liu ${ }^{3}$ \\ ${ }^{1}$ Beijing Jinghang Research Institute of Computing and Communication, Corporation Applied \\ Mathematics Research Center of China Aerospace Science and Industry, Innovation Center for \\ Intelligent System on Recognition and Decision, Beijing, China \\ ${ }^{2} 32021$ Troops, Beijing, China \\ ${ }^{3}$ Equipment project management center, Beijing, China
}

\begin{abstract}
In information war, the concept of "digital battlefield" is put forward, and battlefield meteorological and marine information has become an important part of digital battlefield. Based on the in-depth analysis of the impact of meteorological marine information on cruise missile, this paper puts forward the multi-dimensional demand analysis method of meteorological marine information supporting cruise missile combat application and the architecture design method based on MBSE, and gives the conceptual design framework of combat application system to provide information support for cruise missile combat application.
\end{abstract}

Keywords: Military communication equipment, System adaptability, system integration degree, System contribution rate.

\section{Introduction}

Combat is inseparable from the understanding of the battlefield. Military is a social activity centered on the preparation and implementation of war. With the rapid development of human society towards informatization, the content of information confrontation in high-tech wars in the future will be higher and higher, especially in local wars under high-tech conditions. Due to the characteristics of sudden outbreak of war, accelerated war process and fleeting fighter aircraft, there are higher requirements for the timeliness of battle command ${ }^{[1]}$. Intelligent command and decision-making, automatic battle command and informatization of weapons and equipment have become the key to win the future $\operatorname{war}^{[2]}$. Under this demand, there is a digital battlefield ${ }^{[3-5]}$. Digital meteorological and marine information has become one of the necessary conditions for command and decision-making ${ }^{[6-8]}$. With the expansion of combat space, the support scope of meteorological and marine battlefield environment is gradually expanding, and the conventional prediction technology cannot meet the needs ${ }^{[9-10]}$. We must use the methods of big data analysis, calculation and verification to effectively combine the relevant data

\footnotetext{
*Corresponding author: houjhouj@163.com
} 
collection, perception, cognition and final decision-making, so as to create the advantages of transparent perception, insight prediction and intelligent decision-making of battlefield environment.

\section{Introduction of model-based system engineering method}

In 2007, the international society of Systems Engineering (INCOSE) put forward the definition of MBSE in system engineering 2020 Vision: "the formal and standardized application of modeling behavior of system requirements, design, analysis, verification and validation, which starts from the system conceptual design stage and runs through the system development and subsequent life cycle." INCOSE emphasizes that MBSE is the development trend of future system engineering methods and technologies and a change in the field of system engineering. It first put forward the MBSE long-term plan at the meeting and plans to realize the gradual maturity of MBSE theory and practice system from 2007 to 2020, which means that MBSE will become an important development direction of system engineering in the future ${ }^{[11]}$.

\section{Operational application architecture design of meteorological environment support cruise missile based on MBSE}

\subsection{Construction of operational activity model diagram}

The operational activity model diagram is mainly used to describe various activities that weapons and equipment need to carry out in the process of performing a mission. Operational activity model diagram is the key view to establish the relationship between operational activities and equipment capability. Its modeling steps are as follows: firstly, establish the operational activity node tree to describe the content of operational activities hierarchically; Then, using IDEF0 method as the design basis, the operational activity node tree is transformed into operational activity model design, and how to carry out information interaction among various activities is described in detail; Finally, the operational activity model is decomposed layer by layer from top to bottom until it meets the level required by operational requirements. Combined with the operational process and main operational activities of spatial information support missile defense system, a node tree model of missile defense operational activities including early warning detection, command and control, interception operation and damage assessment is established, as shown in Figure 1.

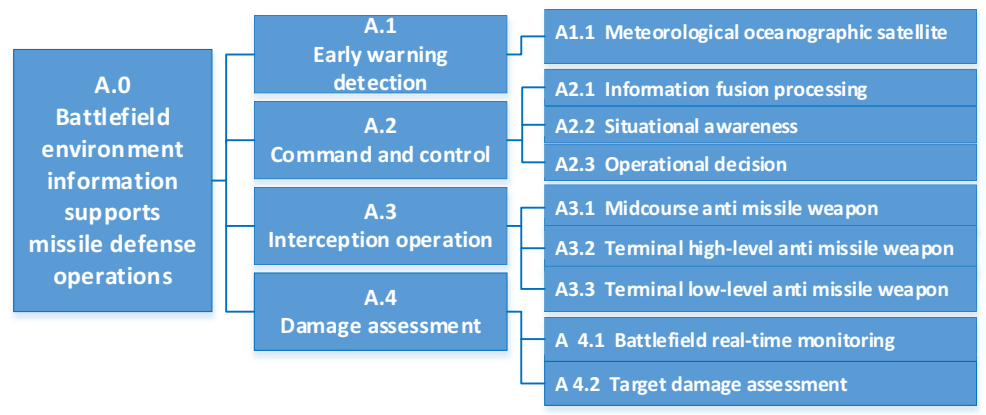

Fig.1. Node tree model of battlefield environment information supporting missile defense operations. 


\subsection{Conceptual design framework of operational application system}

With the deepening of the new military reform, the way of weapon equipment combat capability has changed from the past "threat driven" mode to "operational design" and "concept driven" mode, which also provides a new idea to solve the problem of insufficient traction of operational requirements on the development of weapon equipment construction. The reverse analysis method based on combat requirements demonstration can provide a new means for weapon equipment demonstration and provide some technical support for promoting the transformation of combat effectiveness generation mode. The conceptual design framework of operational requirements demonstration of spatial information support missile defense system based on reverse analysis method is shown in Figure 2.

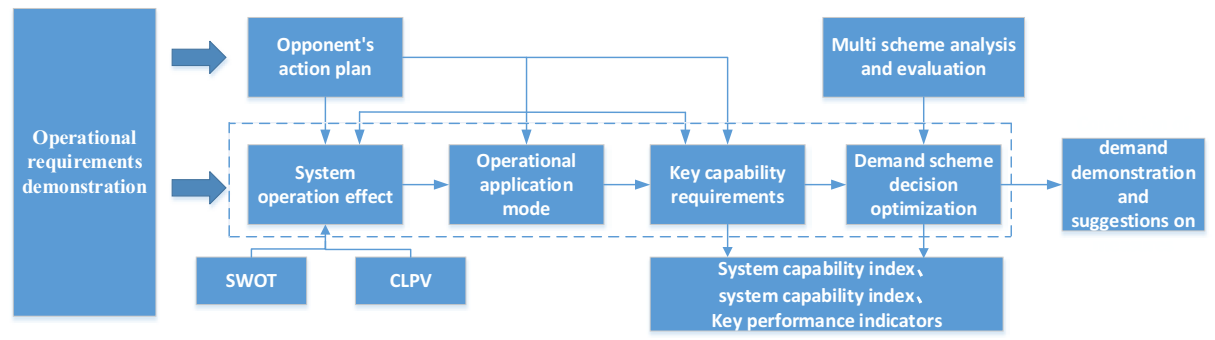

Fig. 2. Conceptual design framework.

The main concepts involved in the reverse analysis method are strategic objective, combat effect, mission, combat action, combat application mode, key capability requirements, equipment requirements analysis, multi scheme analysis, etc.

1) Strategic objectives. Strategic objectives are the objectives, standards and levels to be achieved strategically within a certain period determined by the state or political group. The use of all means of national power (diplomacy, information, military, economic, or dime action for short) should be subject to and serve it. It mainly includes: strategic interest analysis, future national (military) strategic trend analysis, operation theory, military threat analysis (possible conflict, possible intensity of conflict and operation style), etc.

2) Combat effectiveness. Combat effectiveness is the general term for weapons and equipment to damage enemy targets or personnel and cause further impact. The operational effect includes not only the direct effect of damaging the opponent's target or personnel, but also the impact on the operational system after the target is damaged. The former is the hard damage effect of combat, while the latter belongs to the category of soft damage. Operational effect is the link between strategic objectives and missions, mainly including physical effect, functional effect, psychological effect and system effect based on "leverage, inhibition, vulnerability and problem" effect analysis.

3) Mission. Mission and task is the action and responsibility of weapons and equipment to achieve specific operational objectives under certain operational environment, constraints and operational objects. Among them, mission is a command or instruction issued by the superior to achieve a specific operational purpose, which is composed of operations; Tasks are various activities based on doctrine, organization, training, tactics and standard operating procedures to complete combat operations.

4) Combat operations. Combat operations are military activities taken in support of missions and tasks. In order to change the desired state of the joint points of the opponent's combat system, physical effect action, functional effect action, psychological effect action and system effect action can be taken for the opponent's combat system. Joint point refers to the most critical, vulnerable and leveraged node group and link group in the system. It is 
the most effective action point for our own side to shake, disintegrate and even control the opponent's combat system.

5) Operational application mode. The operational application mode is to plan the operational application and operational style of weapons and equipment, form a complete concept of operations (CONOPS) scheme solution of weapons and equipment, and realize the preliminary analysis, judgment and creative conception of the operational application of weapons and equipment. In order to determine the operational capability requirements of weapons and equipment, it is necessary to decompose the mission in combination with the operational concept and operational scenario, so as to obtain the operational tasks and specific operational activities of weapons and equipment, so as to further determine the operational requirements of weapons and equipment.

6) Key capability requirements. It mainly puts forward the key performance indicators, capability characteristics and key technology system that weapons and equipment need to have to complete specific tasks in a certain combat environment. The combat capability of weapons and equipment is mainly composed of information capability (early warning detection and intelligence reconnaissance capability, information attack and defense capability), lethality (Firepower Strike Capability), mobility (three-dimensional mobility capability), command and control capability (command and control capability), protection capability (all-dimensional protection capability), support capability (combat support capability, logistics support capability and equipment support capability).

7) Equipment requirements analysis. It is to study and put forward the ways to realize the new equipment to meet the needs of key capabilities. Equipment requirements analysis focuses on answering questions such as what kind of weapon equipment system is needed, how the relationship between different weapon equipment systems is, and how to meet the requirements of combat capability. Map the results of combat capability requirements to specific equipment. What combat capabilities are needed in future operations, there should be corresponding functional types of weapons and equipment. This correspondence needs to be further refined to form a lower level variety and family requirements of weapons and equipment.

8) Multi scheme analysis. It involves the effectiveness analysis, survivability analysis, operational applicability analysis, cost analysis, risk analysis of weapons and equipment, as well as the sensitivity analysis of multiple schemes to the possible changes of key setting conditions or key variables.

\section{Conclusion}

The combat application of battlefield environment information supporting typical weapon platform is a huge, complex, open and dynamic system. The model-based system engineering method can quickly and effectively guide the development of the architecture of the combat system. It has the characteristics of clear process and strict logic. The application of requirements management tools and design modeling tools can effectively reduce the repeated work of developers, assist developers to verify the design results and continuously improve the design ideas.

\section{References}

1. He Guoliang, Fan Yan-ping, Guo Jie. Analysis Method of Equipment Combat Capability Requirement[J]. Journal of Academy of Armored Force Engineering. 2016, 30(002):1-5. 
2. Fan Y P, Guo Q S, Zhao K. Capabilities-based R equirement Demonstration Method for Weapon System-of-systems[C]. Proceedings of 17th International IEEE Conference on Intelligent Transportation Systems. Los Angeles: IEEE Press, 2014: 200-204.

3. Analysis of Contribution Degree Based on Rule-Based Reasoning for Naval aviation Operation Equipment System[J]. Command Control \& Simulation, 2015, 19(1): 29-33.

4. JEFFREY A NYSTUEN, SUE E MOORE, PHYLLIS J STABENO. A sound budget for the southeastern Bering Sea: Measuring wind, rainfall, shipping, and other sources of underwater sound[J]. JASA, 2010, 128(1): 58-65.

5. NYSTUEN JA, MOORE S E, STABENO P J. A sound budget for the southeastern Bering Sea: Measuring wind, rainfall, shipping, and other sources of underwater sound [J]. JASA, 2010, 128 (1): 58-65.

6. NYSTUEN J A. Spatial averaging of oceanic rainfall variability using underwater sound: Ionian Sea rainfall experiment 2004[J]. JASA, 2008, 123(4): 1952-1962.

7. LINDA B B. Application of model based systems engineering methods to development of combat system architectures[R]. Monterey, California: Naval Postgraduate School, 2009: 65-66.

8. Shen Yuanhai, Hong Liang, Liu Tong, et al. Study of model aggregate for shipborne combat system[J]. Ship Science and Technology, 2009, 31(9): 141-143.

9. Xu Songlin, Qin Dongsheng. Modeling and Simulation Application of Sea Wind Field[J]. Ship Electronic Engineering, 2015.

10. Li Wenhua, Song Jian, Du Jialu, et al. Simulation of Wind Disturbances for Ship Dynamic Positioning in Marine Envioronment[J]. Computer Simulation, 2012(11):154-157.

11. Sun Yu, Liang Yan, MA Li. Application for model based systems engineering and SysML[J]. Information System Engineering, 2012(10): 114-118. 